\title{
Ethics and ethics committees: HIV serosurveillance in Scotland
}

\author{
D M Tappin and F Cockburn Royal Hospital for Sick Children, Glasgow
}

\begin{abstract}
Authors' abstract
Knowledge of the heterosexual spread of HIV is needed to plan future health-care needs. In December 1989 we gained approval and finance for unlinked anonymous testing of neonatal Guthrie card samples in Scotland. Local ethics committee approval was required before testing could start. Twenty ethics committees were approached in the 15 Scottish health board areas. Nineteen of the committees have agreed, representing 99.6 per cent of births in Scotland. Our method of contacting ethics committees is discussed, as are the points raised.
\end{abstract}

\section{Introduction}

On the 24th of November 1989, a government announcement by Virginia Bottomley cleared the way for anonymous unlinked testing for Human Immunodeficiency Virus (HIV) (1). This information is urgently required to allow health-care planning for future patients with Acquired Immune Deficiency Syndrome (AIDS). The pioneering study in Massachusetts USA (2), led to my (Tappin) preparation, in April 1988, of a protocol for anonymous unlinked HIV testing of the childbearing Scottish population using the Guthrie card blood sample. The project was discussed with the National Neonatal Screening Laboratory at Stobhill, Glasgow. Ethics committee approval was granted by the Committee of the Royal Hospital for Sick Children and the Queen Mother's Maternity Hospital, Glasgow in May 1989. A grant application was made to the Medical Research Council (MRC) and funding given for an initial 21-month period. The MRC stipulated that individual area ethics committees were to be approached to give approval prior to the study starting in that health board area. My aim was to gain this approval.

\section{Methods}

POPULATION, HEALTH BOARDS AND ETHICS COMMITTEES

Scotland, with a population of approximately five million, is divided into 15 health board areas (see

\section{Key words}

Research ethics committees; HIV serosurveillance. figure). Most of the population reside in the middle of the country, with sparse numbers to the North and South.

Each health board does not necessarily have a single ethics committee and up to three had to be approached in a single health board area. Twenty ethics committees were approached in the 15 Scottish health board areas.

\section{Contacting ethics committees}

There was no recognised system for contacting all the relevant ethics committees. We decided to use our close liaison with paediatricians in Scotland. A letter was drafted and sent to all consultant paediatricians by Cockburn on 22/9/89 asking them to discuss our study with their nursing and obstetric colleagues and then to present the project to their local ethics committee. A number of problems occurred with this method of contacting ethics committees.

After one month those ethics committees who had not responded were contacted by Tappin and sent a more detailed protocol. Tappin became the contact for all ethics committees and fielded many of their questions.

\section{Results}

The table shows the dates of ethics committee approval, with the cumulative percentage of all Scottish births covered (based on births in Scotland in 1988). Testing started on the $15 / 1 / 90$ in those areas with ethics committee approval. By this time, areas in which half of all Scottish births took place had given approval. Orkney, representing only 250 births per annum, would not give approval for the study. All other areas have subsequently given approval. Thus we are testing cards covering $\mathbf{9 9 . 6}$ per cent of Scottish births.

\section{Discussion}

To plan for the care of future AIDS patients we need to estimate the number of individuals who are HIVpositive. At present at-risk groups, such as homosexual men and intravenous drug abusers will make up the majority of HIV-positive individuals (3). In the future, spread in the heterosexual non-drug-abusing population is likely to increase. A government 


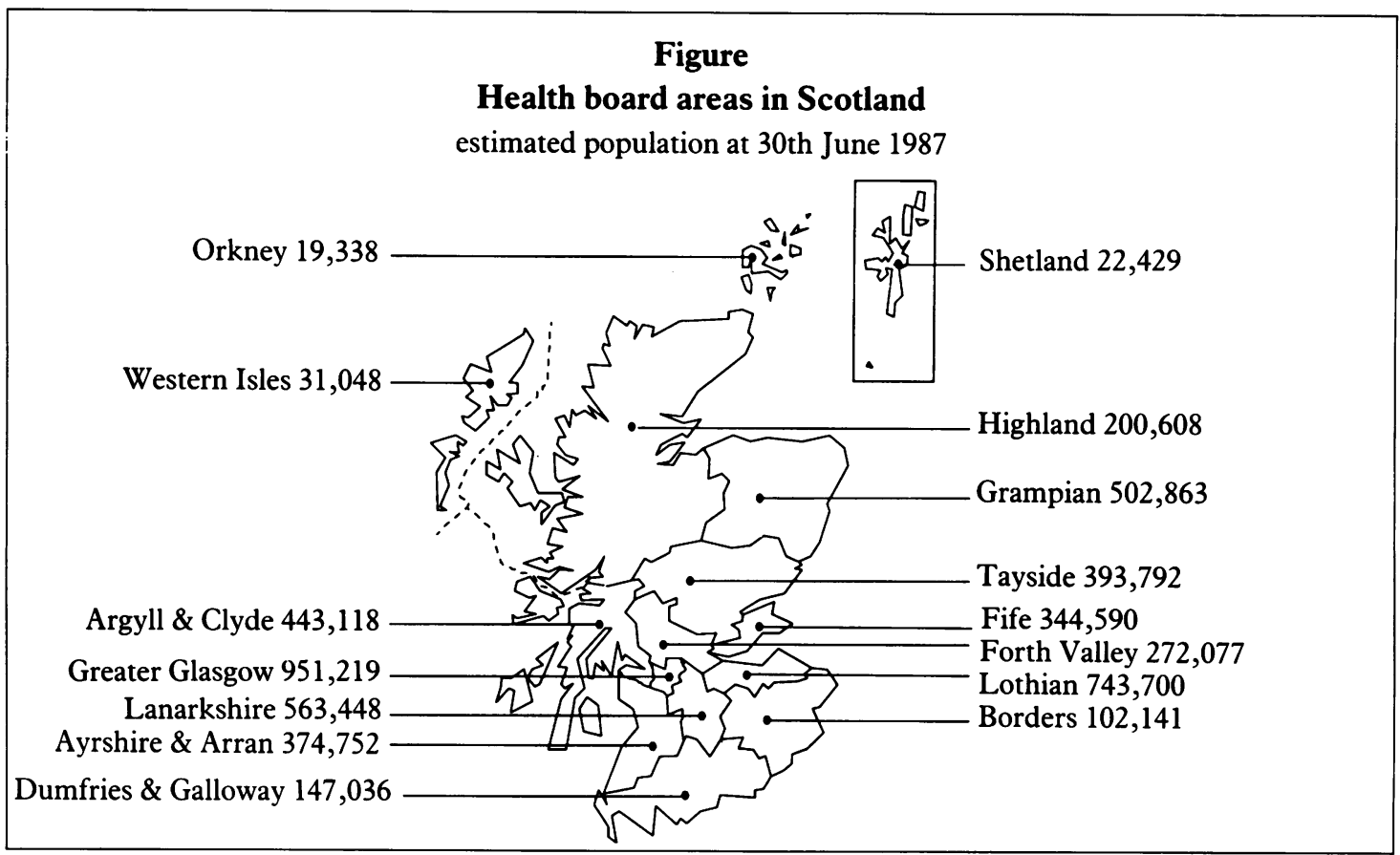

The distribution of the Scottish population

announcement by the health minister in November 1989 (1) cleared the way for unlinked anonymous testing for HIV in the United Kingdom.

Relatively unbiased estimates of the incidence of HIV infection in the heterosexual population can be produced by unlinked anonymous testing of childbearing women. Two blood samples are available, firstly that taken for testing all pregnant women for rubella and secondly the Guthrie card sample taken from all newborn babies, which gives the mother's HIV-antibody status. Both methods are being used, the Guthrie test in Scotland, London and most of the United States of America and the rubella test in certain parts of England and Wales. Each has its own

Table

Dates of individual ethics committee approval

\begin{tabular}{|c|c|c|}
\hline Health board area & $\begin{array}{c}\text { Date of ethics committee } \\
\text { approval }\end{array}$ & $\begin{array}{l}\text { Cumulative \% total } \\
\text { Scottish births covered }\end{array}$ \\
\hline Greater Glasgow & 11 May 1989 & $20 \%$ \\
\hline Perth and Kinross & 10 November 1989 & $22 \%$ \\
\hline Lothian & 23 November 1989 & $36 \%$ \\
\hline Borders & 5 December 1989 & $38 \%$ \\
\hline Fife & 5 December 1989 & $44 \%$ \\
\hline Highland & 15 December 1989 & $48 \%$ \\
\hline Paisley and Renfrew & 1 February 1990 & $54 \%$ \\
\hline Grampian & 7 February 1990 & $64 \%$ \\
\hline Ayr and Arran & 20 February 1990 & $71 \%$ \\
\hline Forth Valley & 27 February 1990 & $76 \%$ \\
\hline Vale of Leven & 28 February 1990 & $78 \%$ \\
\hline Dumfries and Galloway & 6 March 1990 & $81 \%$ \\
\hline Western Isles & 15 March 1990 & $82 \%$ \\
\hline Angus & 28 March 1990 & $83 \%$ \\
\hline Dundee & 23 April 1990 & $87 \%$ \\
\hline Shetland & 14 May 1990 & $88 \%$ \\
\hline Lanarkshire & 14 June 1990 & $98 \%$ \\
\hline Argyll & 11 July 1990 & $99.6 \%$ \\
\hline
\end{tabular}


drawbacks but both methods give similar information.

A protocol for a study in Scotland, similar to the Massachusetts study (2), was submitted for local ethical approval and for funding. All Guthrie cards from the 65,000 births in Scotland are sent to the National Neonatal Screening Laboratory at Stobhill Hospital in Glasgow. This central collection and testing made the Guthrie method more attractive than the rubella test in Scotland. The MRC funded our study but ethics committee approval was required from each health board area in Scotland.

The major initial dilemma was which ethics committees should be contacted to request approval for a national study. One approach would have been to send the protocol directly to each health board Chief Administrative Medical Officer (CAMO). After much discussion we felt this would not be the most expedient way and would place an additional burden on the CAMOs. Consultant paediatricians have a responsibility for dealing with Guthrie card results for phenylketonuria, galactosaemia and hypothyroidism and it was felt that an approach to local ethics committees through the local paediatrician, after discussion with his obstetric and health-visiting colleagues, would be the most appropriate method. Although there were some complaints about this approach, we were able to obtain approval from Glasgow, Lothian, Highland, Fife, Perth and Kinross (part of Tayside) and Borders without too much opposition. These boards cover half the population of Scotland (see figure). The other ethics committees were informed of those who had already agreed and after considerable further discussion and deliberation slowly, one by one, they gave their approval.

A problem arose with this method of contacting all relevant ethics committees in that the Hebridean Island health boards do not have separate paediatricians and were not contacted until February 1990, which obviously delayed approval. Due to a misunderstanding with an Argyll and Clyde health board administrator, the existence of a separate ethics committee for Argyll was not known to us. Only by asking the secretary to another ethics committee in the area was I (Tappin) able to find out about Argyll. Once identified, the committee was helpful and expeditious.

The jurisdiction of a single ethics committee is not well defined, but in a single city the unwritten arrangement is that if a well respected ethics committee passes a protocol then other committees in the city will accept its judgement and further formal application is not needed. In Glasgow the jurisdiction of the initial ethics committee approval was challenged. The project was presented to a further ethics committee covering the southern half of the city and passed without problems. Dealing with small health board areas was in general simpler. Ethics committees run in close liaison with health boards and contact is straightforward. Lanarkshire had no ethics committee and this meant a six-month wait until a committee was appointed.

Ethics committees raised a number of important questions. Government information on anonymous HIV testing (4) outlining procedure in the case of spontaneous refusal was not appropriate to neonatal Guthrie card testing. The government document advised counselling of all individuals who spontaneously refused testing. These recommendations were presented to one ethics committee which was initially surprised and not in agreement with the instruction. They were then outraged when it was decided this recommendation should not apply to Guthrie card testing. I (Tappin) learnt the lesson of being very careful about the information I sent to ethics committees. No instructions were available to health care workers taking the Guthrie card samples with specific reference to spontaneous refusal; instructions were drafted and, with slight alterations, became part of the guidelines from the Scottish Office (5).

The government announcement of 24/11/89 (2) did not specifically state that Guthrie card testing would start on the 15/1/90. This caused some disquiet among a number of ethics committees and others, notably individuals representing health care workers taking the blood samples. Both problems were later resolved by a Scottish Home and Health Department circular (5).

Worry was expressed as to indirect identification of individuals and explanation and reassurance was given. The Shetland Islands, with a very small closeknit community, felt that one positive result would provoke a witch-hunt. We therefore decided to integrate all island results with a larger mainland area.

The only refusal was from the Island of Orkney. After two approaches its committee felt that the women whose babies were tested HIV-positive should be informed. We could not comply with this request, as our study was specifically designed to avoid identification of affected individuals.

Significant underestimates of seroprevalence occur in attributable studies where informed consent of the tested individuals is required, even if only a few of the population opt out (6). Ethics committee approval allows us to test 99.6 per cent of Scottish babies, which reflects the seroprevalence in childbearing women in Scotland. The island of Orkney has only 250 births per annum, which is the remaining 0.4 per cent, and is unlikely to affect the validity of our results.

An anonymous unlinked HIV-serosurveillance study is being set up in London using maternal blood samples obtained for rubella-antibody testing. The $\stackrel{\odot}{\subset}$ organiser has approached 30 ethics committees and problems gaining approval have been similar to our own.

Gaining ethics committee approval for a national study is time-consuming. Our liaison with local paediatricians was on the whole successful but did meet with some disapproval from non-paediatricians. National ethics committees have been mooted, but in a sensitive area like HIV, local approval is likely to continue to be needed to allay local fears. 
D M Tappin, MBBS, MRCP, Senior Registrar; F Cockburn, MD, Samson Gemmell Chair of Child Health, Royal Hospital for Sick Children, Yorkhill, Glasgow G3 $8 S f$.

\section{References}

(1) Department of Health. Press release. Virginia Bottomley announces HIV anonymised testing. 1989 Nov 24.

(2) Hoff R H, Berardi V P, Weiblen B J, Mahoney-Trout L, Mitchell M L, Grady G F. Seroprevalence of human immunodeficiency virus among childbearing women: estimation by testing samples of blood from newborns. New England journal of medicine 1988; 318: 525-530.

(3) Human Immunodeficiency Virus (HIV) Infection,
Scotland. AIDS news supplement. Communicable Diseases Scotland (CDS) weekly report 1990 Jul 14; CDS 90/28: ISSN 0956-3040.

(4) Medical Research Council. Arrangements for patients who forbid anonymous testing. Distributed with: Anonymous testing for HIV antibodies without consent: ethical committee approval for studies supported by the Medical Research Council; S819/230 II: 1989 Aug.

(5) Calman K C, Moores Y. Anonymous testing for HIV. Scottish Home and Health Department circular; PAL036P2: 1990 Feb 6.

(6) Hull H F, Bettinger C J, Gallacher M M, Keller N M, Wilson J, Mertz G J. Comparison of HIV-antibody prevalence in patients consenting to and declining HIVantibody testing in an STD clinic. Fournal of the American Medical Association 1988; 260: 935-938. 